\title{
Staying Home, Staying Safe? A Short-Term Analysis of COVID-19 on Dallas Domestic Violence
}

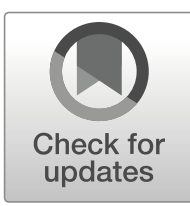

\author{
Alex R. Piquero ${ }^{1,2}$ • Jordan R. Riddell ${ }^{3}$. Stephen A. Bishopp ${ }^{4} \cdot$ Chelsey Narvey $^{5}$. \\ Joan A. Reid $^{6} \cdot$ Nicole Leeper Piquero $^{1}$
}

Received: 4 May 2020 / Accepted: 29 May 2020 /

Published online: 14 June 2020

(C) Southern Criminal Justice Association 2020

\begin{abstract}
COVID-19 has wreaked havoc on the lives of persons around the world and social scientists are just beginning to understand its consequences on human behavior. One policy that public health officials put in place to help stop the spread of the virus were stay-at-home/shelter-in-place lockdown-style orders. While designed to protect people from the coronavirus, one potential and unintended consequence of such orders could be an increase in domestic violence - including abuse of partners, elders or children. Stay-at-home orders result in perpetrators and victims being confined in close quarters for long periods of time. In this study, we use data from Dallas, Texas to examine the extent to which a local order was associated with an increase in domestic violence. Our results provide some evidence for a short-term spike in the 2 weeks after the lockdown was instituted but a decrease thereafter. We note that it is difficult to determine just how much the lockdown was the cause of this increase as the domestic violence trend was increasing prior to the order.
\end{abstract}

Keywords COVID-19 · Domestic violence · Partner abuse $\cdot$ Child maltreatment · Stay-athome $\cdot$ Dallas

Alex R. Piquero

axp1954@miami.edu

1 University of Miami, Department of Sociology, 5202 University Drive, Merrick Building Room 120, Coral Gables, FL 33124, USA

2 Monash University, Melbourne, Australia

3 The University of Texas at Dallas, Richardson, TX, USA

4 Dallas Police Department, Dallas, TX, USA

5 Sam Houston State University, Huntsville, TX, USA

6 University of South Florida St. Petersburg, St. Petersburg, FL, USA 


\section{Introduction}

The coronavirus (COVID-19) pandemic is affecting every country and just about every person in one form or another. Since the United States Centers for Disease Control (CDC) first learned about a cluster of cases in Wuhan, China on December 31, 2019, to the identification of the first U.S. case on January 21, 2020 from a man who returned back to Seattle after traveling to Wuhan, to the first set of cases hitting every state in the U.S., the virus has gained national attention. Policy and government officials, health professionals, scientists, as well as researchers have been at the forefront of a wide range of issues, questions, and responses. In this study, we focus on one issue that may be related to COVID-19: criminal behavior, specifically domestic violence.

On Sunday April 5, 2020, United Nations Secretary António Guterres addressed the issue of domestic violence within the context of international lockdowns associated with COVID-19 by noting: "We know lockdowns and quarantines are essential to suppressing COVID-19, but they can trap women with abusive partners... Over the past weeks, as the economic and social pressures and fear have grown, we have seen a horrifying surge in domestic violence." The UN Secretary also called for nations to plan for the prevention and redressing of domestic violence as part of their overall response to COVID-19 to include efforts to keep domestic violence shelters open as essential services, setting up emergency warning systems in pharmacies and grocery stores, etc. (United Nations, 2020; United Nations Women, 2020). ${ }^{1}$

There are ample theoretical reasons to envision both increases and decreases in crimes during the lockdowns. On the one hand, there could be an increase in crime because people are ordered to stay in their homes, resulting in more people spending more time confined with one another. This could increase the types of negative strains and negative emotional responses, such as anger, that are referred to by Agnew (1992) in General Strain Theory that could be indicative of a crime spike. In fact, on this score, Phumzile Mlambo-Ngcuka, executive director of UN Women, recently stated: "Confinement is fostering the tension and strain created by security, health, and money worries" (Bilyeau, 2020). ${ }^{2}$ Alternatively, there could also be observed decreases in reports of specific types of crime, such as domestic violence, because some victims may be afraid to call the police or domestic violence shelters because their perpetrators are confined with them and can closely monitor their communications.

\footnotetext{
${ }^{1}$ In one unusual policy statement that has since been abandoned, Malaysia's Ministry for Women, Family and Community Development issued a series of online messages advising women to avoid nagging their husbands, to refrain from being "sarcastic" if they asked for help with household chores, and urged women working from home to dress up and wear makeup (Sullivan, 2020).

${ }^{2}$ This problem can be even more magnified if alcohol and/or drug use increases during social isolation periods - and there is some preliminary correlational evidence on this front. Ibotta, a free shopping platform, has analyzed grocery store receipts and has observed large increases in the percentage of alcohol sales throughout the United States - by as much as 50\% in March alone - and in localized jurisdictions such as Miami (Ogle, 2020).
} 
Routine activities theory may also be called upon here to offer predictions of increases or decreases in crime. Predicting more crime, routine activities may anticipate an increase in domestic violence cases because all three conditions specified by the theory would appear to be met: a motivated offender, a suitable target, and the absence of a guardian. There is also the potential for decreases in other crimes (such as robbery and burglary) because fewer people are out in bars and shopping malls and many more are staying at home, thereby reducing - or even eliminating - some of the elements needed for routine activities to successfully anticipate these types of criminal behavior.

In this study, we examine the extent to which a stay-at-home order in Dallas, Texas was associated with any increase in domestic violence defined as abuse or assault against a family member, household member (including previous household members), or a current or past dating partner. Before we present the results of our investigation, we offer a brief overview of the potential effects of lockdowns on two prominent forms of domestic violence - child maltreatment and partner abuse. This is followed by a summary of what is known from both media reports and empirical research on the relationship between lockdowns and crime. We then turn toward our analyses.

\section{Background}

Childhood maltreatment, including abuse and neglect, has been identified as a prevalent and severe public health issue that can lead to a myriad of negative outcomes across the life course. Prevalence rates of maltreatment vary dependent on the type of abuse or neglect. Self-reported incident rates demonstrate that supervision neglect (i.e., being left home alone as a child) is the most common form of maltreatment. According to The National Longitudinal Adolescent Health study (Hussey, Chang, \& Kotch,, 2006), 41.5\% of respondents indicated that they had been left home alone as a child. Physical assault was the second most common form of maltreatment (28.4\%), followed by physical neglect $(11.8 \%)$ and contact sexual abuse (4.5\%). Within the entire country, approximately $37.4 \%$ of children under the age of 18 experience being the subject of a childhood maltreatment investigation at some point in their lifetime (Kim, Wildeman, Jonson-Reid, \& Drake, 2017), with Black youth being most likely to be involved in such investigations (53\%) and Asian youth least likely (10.2\%). Socio-economic status (SES) has also been found to be related to neglect, with children belonging to lower SES families experiencing higher rates of neglect (Vanderminden et al., 2019). Additionally, it is estimated that 1 year of childhood maltreatment investigations costs the country approximately $\$ 585$ billion, roughly 4\% of the US gross domestic product in 2010 (Fang, Brown, Florence, \& Mercy, 2012).

Childhood abuse and neglect also has long-lasting psychological effects on children. On this score, all forms of maltreatment (supervisory neglect, physical assault, physical neglect, and sexual assault) have been associated with increased trauma symptoms and suicidal thoughts in children aged 10-17, as well as an increased risk of underage drinking and illicit drug use (Vanderminden et al., 
2019). Child abuse has also been linked to issues throughout adulthood, including a higher likelihood of mental health problems such as depression, and a decrease in intellectual and cognitive development (Anda et al., 2006; Lansford et al., 2002; Sousa et al., 2018). Individuals who have experienced childhood maltreatment also demonstrate a limited ability to deal with stress and an increase in antisocial behavior (Currie \& Tekin, 2012; McCrory, De Brito, \& Viding, 2011; Widom, Fisher, Nagin \& Piquero, 2018). Additionally, the effects of maltreatment lead to worsened health across the lifespan and are linked to increased mortality in adulthood (Anda et al., 2006; Jonson-Reid, Chance, \& Drake, 2007).

Risk factors for maltreatment have been extensively studied in the literature. Distinct demographic, socioeconomic, and familial factors have been found to be associated with childhood abuse and neglect. As aforementioned, children in lower SES families are more likely to be subjected to childhood maltreatment. At the county level, rates of neglect have been positively associated with rates of births by teens, percentage of births by unmarried mothers, drug-related offenses, and percentages of children receiving supplemental nutrition program (SNAP) benefits (Morris et al., 2019). More proximal factors that increase risk of childhood maltreatment include mother's unhappiness, stress and reactivity, father's drinking, and children's problem behavior. Parents' age has also been inversely related to maltreatment, with younger parents being more likely to abuse and neglect their children (Black, Heyman, \& Slep, 2001).

The COVID-19 stay-at-home orders are creating major disruptions in daily life. The cessation of many face-to-face interactions due to the mandated responses to the pandemic has disrupted the lives of all Americans, especially the lives of families with children. These families are struggling to figure out how to meet the health, well-being, and educational needs of their children. Caregivers are coping with closures to schools and childcare facilities and they must now take on the daily demands of overseeing the educational needs of their children. Risk for child maltreatment may be elevated when families and caregivers are dealing with such stressful conditions. Caregiver adversities and strains have been repeatedly identified as key risk markers that increase the likelihood of child abuse and neglect (see Agnew, Rebellon, \& Thaxton, 2000). Agnew et al. (2000) theorized that caregiver strain produces negative emotions in the caregiver, which are commonly expressed by caregivers withdrawing from or neglecting their nurturing responsibilities. Caregiver strains and family adversity, including lack of social support, economic hardship, unsupportive family structure and domestic violence may result in failed nurturing and child maltreatment (Agnew et al., 2000).

Most importantly, mandated responses to the COVID-19 pandemic have altered the availability of health and social service resources typically relied upon by vulnerable children and their families. Reduced social and educational support is particularly challenging for those families whose members have behavioral or mental health needs, medical needs, families with co-custody arrangements, or children in foster care or at risk for child maltreatment. School and childcare personnel function as guardians for children at risk for maltreatment and provide the highest percentage of referrals to child protection agencies (U.S. Department of Health \& Human Services, 2020). With children mandated to stay home rather than attend school or go to childcare, many incidents of abuse may go undetected or unreported. 
Beyond the effects of the stay-at-home order on child maltreatment, another important consideration is the amount of conflict between partners. Researchers have confirmed that varied forms of family violence often occur in tandem, with strong associations between partner abuse and child maltreatment (Herrenkohl, Sousa, Tajima, Herrenkohl, \& Moylan, 2008).

Similar themes are evident within the context of family, domestic, and intimate partner violence. Due to the COVID-19 pandemic, levels of family adversity have increased in unprecedented ways. Many have lost their jobs and sources of income, while others are worried over future economic uncertainties. Times of financial stress and problems at work, possibly moderated by alcohol use, have been linked to perpetration of partner abuse by both men and women (Capaldi, Knoble, Shortt \& Kim, 2012). As partner abuse can be driven by a need for power and control, when life spins out of control at work or financially, individuals find it difficult to cope with these pressures and may become abusive toward their family members.

Stay-at-home orders may have unintentionally compounded the threat for domestic violence victimization by trapping at-risk partners at home and disrupting access to social support and social service resources typically available to them. The mandated stay-at-home orders even mimic common forms of partner abuse such as forcing isolation from friends and family, preventing the victim from working or attending school, and generally controlling the victim's associations, movements, and activities (National Domestic Violence Hotline, n.d.). With stay-at-home orders, those at risk for partner abuse are unable to seek safety or assistance from family, friends, or service providers.

\section{Lockdowns \& Crime}

Much of the early investigations surrounding potential crime increases due to coronavirus have been published by the media, with activists and academics weighing in with their predictions. There are some initial indications and a few case studies surrounding the potential rise in crime associated with COVID-19 and the ensuing lockdown orders around the world (Wagers, 2020). In the state of Texas, the locale of our analysis, there have been stories about a potential rise in child abuse in Fort Worth (Solis \& Martinez, 2020), reported increases in domestic violence, assault, and burglary in Houston (CW39, 2020), reported increases in domestic violence cases by the District Attorney of Montgomery County (Gonzalez, 2020), and increases in Google-based searches for help with domestic violence (Neuman, 2020; Townsend, 2020). On the other hand, preliminary data from Miami-Dade County (Florida) show that domestic violence arrests decreased throughout March (Ovalle \& Rabin, 2020) and other data from Florida suggests that child abuse cases have decreased (McKinnon, 2020). ${ }^{3}$ Relatedly, according to RAINN, the Rape, Abuse and Incest National

\footnotetext{
${ }^{3}$ This is not entirely surprising as teachers are often the first to see child abuse when children come to school, but with schools shuttered many cases are going undetected.
} 
Network, which manages the National Sexual Assault Hotline, during March there was a $22 \%$ increase in calls to the hotline (Kamenetz, 2020). For the first time in the history of the hotline, half of the calls came from minors. Of the minors who called the hotline, $67 \%$ reported their perpetrator was a family member and $79 \%$ reported that they were currently living with that perpetrator.

Analyses from the Associated Press (2020) providing an 'early-look' at several cities throughout the United States (and around the world) also show reductions in crime. Concurrently however, there have been increases in calls to mental health and suicide prevention hotlines during the time period of many stay-at-home orders (Goodman, 2020; Jackson, 2020).

At the same time, there has been little systematic examination of how the COVID-19 virus and the various stay-at-home orders have affected crime one way or the other from the academic and research community in large part due to data limitations. For the most part, available information tends to suggest little increase in crime throughout the United States (see Ashby, 2020; Shayegh \& Malpede, 2020; Weichselbaum \& Li, 2020; Campedelli et al., 2020). Using crime data from 17 large U.S. cities, Ashby (2020) used crime data in previous years in order to forecast the expected frequency of crime in the early part of 2020. His results showed that there was little change or even decreases in some crime types but the effects were not uniform across all the cities. In one Australian study, Payne, Morgan, and Piquero (2020) used monthly violent crime (common assault, serious assault, sexual offenses and breaches of domestic violence orders) data for Queensland, Australia in order to model the monthly offense rate between February 2014 and February 2020. (Most restrictions took place in the month of March throughout Australia, with a combination of federal and territory restrictions). They used the 2014-2020 data to forecast March 2020 data and then compared the forecast to the actual crime that was recorded in March 2020. Results showed that rates of recorded crime in March across the four violent crime categories did not differ from the forecast, and in most cases the actual March 2020 crime figures were lower than the forecasts generated.

\section{Current Focus}

Overall, there has been much more media reporting of potential short-term changes in crime due to COVID-19. In particular, the media has focused on the various stay-at-home policies that have been mandated. However, there have been few rigorous empirical analyses from the research community. Among those that have been conducted, the preliminary conclusion is that there is only limited support for the suggestion that COVID-19 and its associated containment measures has had an impact on violent crime and, in the more robust (but short-term) studies, there has been no strong evidence of an impact on domestic violence. Other studies around the world looking at domestic violence reveal mixed results, with some evidence of increases in some places but decreases in others. Nevertheless, most media reports and 
empirical studies have been short-term, not providing for an adequate time of observation after stay-at-home style orders have been implemented.

Our study was designed to overcome the 'time-frame' limitation. In particular, we use data from the Dallas Police Department to examine whether the stay-athome order served as a 'negative' intervention, so to speak, that was associated with an increase in domestic violence. Our time frame includes more observed (daily) points of data than what has been found in the extant literature, thereby giving us greater confidence in our ability to detect both short-term and longerterm trends that occurred after the lockdown was instituted compared to a lengthy 'pre-lockdown' period.

Specifically, this study provides an initial, short-term examination of how COVID-19 and responses by the city and county of Dallas have affected one type of criminal activity, domestic violence. Using an array of modeling strategies, we examine how domestic violence crimes changed following the Dallas stay-at-home order on March 24, 2020.

\section{Methods}

\section{Data}

The city of Dallas, Texas is the site of our investigation. As of July 1, 2019, the city had a population of 1,300,000 individuals, making it one of the country's ten largest cities (coming it at \#9). The city is part of the DallasFort Worth metroplex, which is the fourth largest metropolitan area in the United States. The city of Dallas and its surrounding counties is also home to a large number of Fortune 500 companies.

Public safety in the city of Dallas is overseen by the Dallas Police Department (DPD), which has over 3500 sworn personnel and over 500 civilian employees. Like in any other major city, Dallas has experienced its fair share of crime increases and decreases-depending on the year and crime type. Most recently, 2019 saw the city experience a large surge in the number of homicides. Yet during the first quarter of 2020, homicides were down significantlyas were many other violent crimes with the exception of aggravated assaults. Nevertheless, for most of the first quarter of 2020, most violent and non-violent crimes were holding steady with some slight fluctuations.

The DPD requires officers to enter all reports into the report management system (RMS). Any call or self-initiated activity (e.g., traffic stop) triggers the creation of an incident number. If, as a result of the incident, officers encounter a situation where a report must be completed, they will log into the DPD field-based reporting system and complete the report. Before submitting their report, officers are required to indicate if the incident is a domestic violence-related report by marking "yes" or "no" from a dropdown menu. After the report is completed, it is assessable in RMS and all data in the report are extractable. In fact, crime analysts pull data from RMS daily and create descriptive analyses for command staff members. 
One type of report created by DPD crime analysts, and the focus of the current study, is the Family Violence Incident List. ${ }^{4}$ Data recorded in the Family Violence Incident List include misdemeanor and felony domestic violence, child abuse, elderly abuse, and sexual assault for offenses. Misdemeanor domestic violence includes harassment, interference with 911 calls, unlawful restraint, deadly conduct, and arrest warrant arrests. Felony domestic violence includes aggravated assaults, violations of protective orders, and strangulation offenses. Child abuse includes offenses such as indecency with a child (persons $<17$ years old) and sexual assault of a child. Elderly abuse means a crime committed against someone who is 65 or older, while sexual assaults are those offenses committed against adults. ${ }^{5}$

For this study, we rely upon domestic violence incident reports that occurred between January 1st, 2020 and April 27th, 2020, for a total of 118 days of incident counts. An index of daily counts of all domestic violence incidents in Dallas was created by summing together misdemeanor, felony, child, elderly, and sexual assault family violence incidents. In Table 1, descriptive statistics for total domestic violence and individual categories are displayed. The daily domestic violence incident count is the dependent variable in this study.

Following the Dallas County order issued by Judge Clay Jenkins, the City of Dallas similarly adopted the 'stay-at-home' order on March 24th, 2020, with regulations taking effect on the same day. Appendix A includes all of the necessary details regarding the various lockdown orders in the City of Dallas, Dallas County, and the State of Texas. An indicator variable was created to represent the stay-at-home order intervention, with the 83 days before March 24th (January 1st to March 23rd) coded as zero and March 24th and afterwards (March 24th to April 27th) coded as one for the 35 day postintervention period.

\section{Analytic Plan}

We take multiple approaches to test the effect of the stay-at-home order on domestic violence in the city of Dallas. First, we created a simple descriptive graph depicting domestic violence crime counts for the entirety of the data, as well as a 6-week window

\footnotetext{
${ }^{4}$ The DPD has a Domestic Violence Unit, which is a specialized investigative office that responds to domestic violence in the city. The Unit is comprised of a sergeant, detectives, a crime analyst, and a civilian counselor. Since its creation in 1987, the Unit investigates and prepares cases against persons responsible for domestic assaults and frequently partners with community agencies (https://dallaspolice. net/division/familyviolence/familyviolencesquad). It is also worth noting that the City of Dallas created a Domestic Violence Taskforce in 1987 as a result of a class action lawsuit against the city (https://dallascityhall. com/government/citycouncil/district13/dvtf/Pages/Task-Force-History.aspx). Finally, the Dallas City Attorney's Office has a Family Violence Unit located within it which is a special unit that prosecutes Class C Misdemeanor family violence cases in the city, which usually involve lower risk offenses (http://www. dallascityattorney.com/Domestic_Violence.html). As can be seen, multiple agencies within the city have a focus on the domestic violence issue.

${ }^{5}$ Family includes current or former spouses, parents of the same child, without regard to marriage, and without regard to whether those individuals reside together. Household means persons currently or previously living together in the same dwelling, without regard to whether they are related to each other (Texas Family Code, 2019). Offenses occurring between individuals in a current or previous dating relationship are also included in this definition.
} 
Table 1 Descriptive statistics

\begin{tabular}{lllll}
\hline Crime Type & Mean & Std. Dev. & Min & Max \\
\hline Domestic Violence & 36.38 & 8.26 & 17 & 62 \\
Misdemeanor & 24.62 & 6.25 & 10 & 45 \\
Felony & 10.49 & 3.59 & 2 & 19 \\
Elderly & 0.37 & 0.57 & 0 & 3 \\
Child & 0.56 & 0.83 & 0 & 4 \\
Sexual Assault & 0.28 & 0.54 & 0 & 2 \\
\hline
\end{tabular}

centered about the intervention date. Next, we conducted a trend analysis using Stata's itsa command that estimates the effect of the stay-at-home order on our daily time series. This test estimates the linear trend in domestic violence before the stay-at-home order, detects any presence of change in domestic violence at the time the intervention began, and estimates the linear trend of domestic violence after the stay-at-home order. We also considered the descriptive graph and the potential for a second change in the trend.

A Dickey-Fuller test ${ }^{6}$ for non-stationarity and a correlogram plot to determine if lagged values are autocorrelated with the domestic violence data series were used. Then, we made use of multiple OLS and Poisson regression models that include the lag terms that are correlated with the data series. Here, the OLS models provide an easy interpretation of the magnitude of the effect of the Dallas stay-at-home order - similar to a difference in means test - and the Poisson regression models are used because our time series consists of count data.

Lastly, we used an autoregressive integrated moving average (ARIMA) forecast model that uses only the data from before the stay-at-home order to predict future domestic violence incidents. Prediction intervals about the point estimates were also generated, allowing us to compare actual domestic violence to domestic violence that would have been predicted with data from before the stay-at-home order began. This was done in order to attempt to understand what crime analysts might have expected to see in domestic violence crime counts before the city's stay-at-home order came into effect. $^{7}$

\section{Results}

The graphs in Fig. 1 provide a visual representation of the entire time series and a restricted 6-week window for domestic violence incidents in Dallas, TX, with the series appearing to follow a moving average pattern. To set up our data for trend analysis, we made use of the Statistical Analysis System (SAS) date format which presents dates as

\footnotetext{
${ }^{6}$ Recall that the null hypothesis in a Dickey-Fuller test is that a unit root is present in an autoregressive model.

${ }^{7}$ The use of a series of different approaches helps to give us confidence in the results that emerge from our investigation (see also Piquero, Piquero, \& Riddell, 2019).
} 

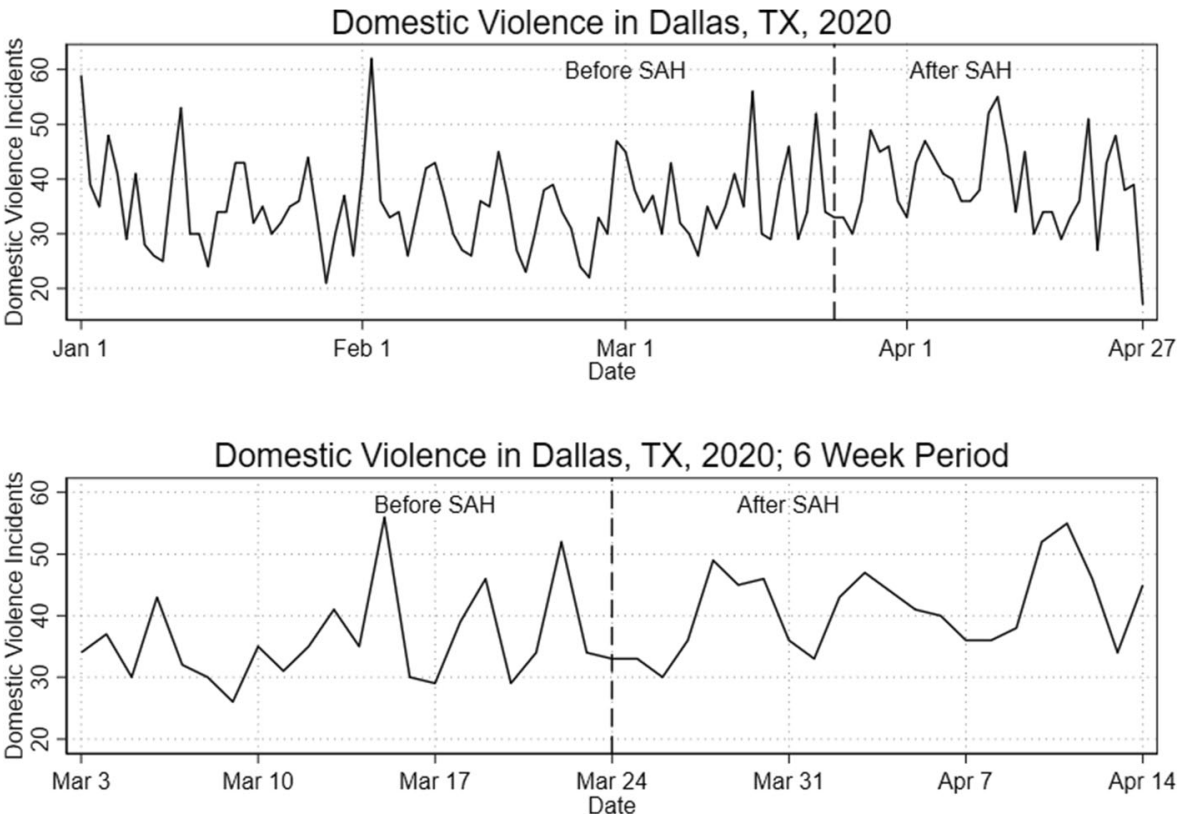

Fig. 1 Domestic violence incidents in Dallas. Two way line plots of daily domestic violence incident counts in Dallas, TX, from January 1st to April 27th, 2020, and a centered look at the 3 weeks before and after the stayat-home order. Domestic violence incident counts are the solid black line, and the dashed vertical line drawn at Mar 24 indicates the beginning of the city's stay-at-home order regulations

the number of days elapsed since January 1st, 1960 (StataCorp. 2019) (e.g., January 2nd, 1960 is 00001). Results of the domestic violence trend analysis are displayed in Table 2, with Fig. 2 graphically portraying the estimated linear models for observed

Table 2 Trend analysis results

\begin{tabular}{lcc}
\hline One break point & Coefficient & Std error \\
\hline Time before stay at home & -0.01 & 0.05 \\
Start of stay at home order (March 24th) & 5.78 & 3.69 \\
Time during stay at home & -0.11 & 0.19 \\
Constant & 35.99 & $2.59 * *$ \\
& & 0.05 \\
Two break points & & 3.43 \\
Time before stay at home & -0.01 & $0.29 *$ \\
Start of stay at home order (March 24th) & 0.36 & 4.46 \\
Time between March 24th \& April 7th & 0.71 & $0.51 *$ \\
Start of second week after (April 7th) & -2.49 & $2.58 * *$ \\
Time after April 7th & -1.15 & 36.02 \\
Constant & & \\
\hline
\end{tabular}

$* p$ value $<.05 ; * * p$ value $<.01$ 


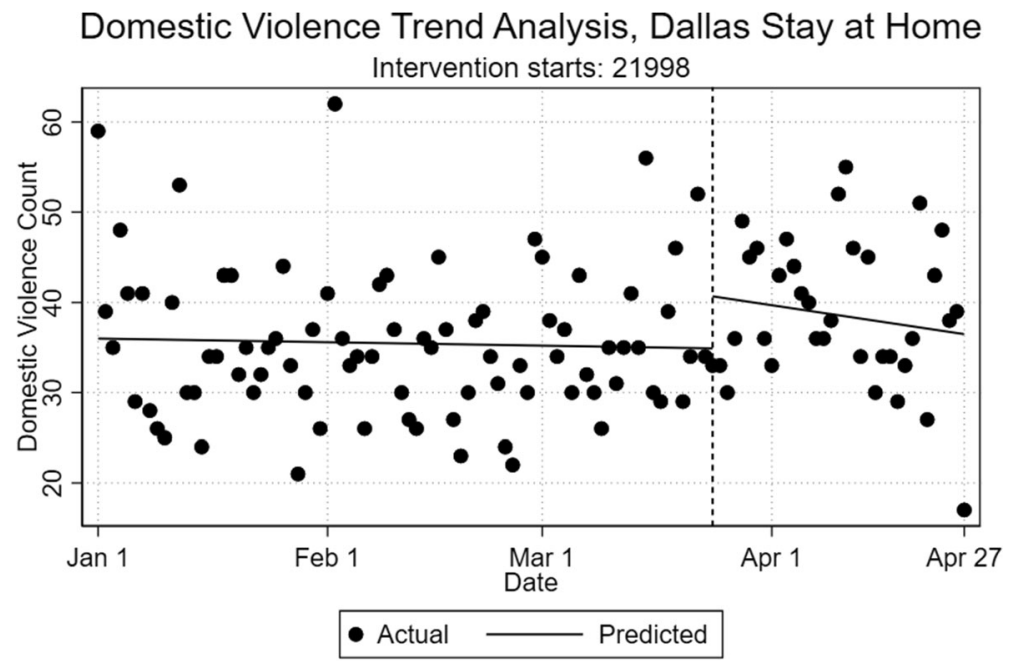

Prais-Winsten and Cochrane-Orcutt regression - $\operatorname{lag}(1)$

Fig. 2 Trend analysis, March 24th (21998) breakpoint. Domestic violence trend analysis for before and after the stay-at-home order. Solid black lines represent the estimated trend and solid black points are observed data. The dashed vertical line is the intervention at March 24th, or 21,998 days after January 1st, 1960

domestic violence before and after the March 24th (SAS date 21,998) stay-at-home order. As can be seen in Table 2, the implementation of the stay-at-home order is not associated with a statistically significant increase in domestic violence incidents, and there is not enough evidence to suggest an upward trend in domestic violence incidents throughout the month after the stay-at-home order went into effect.

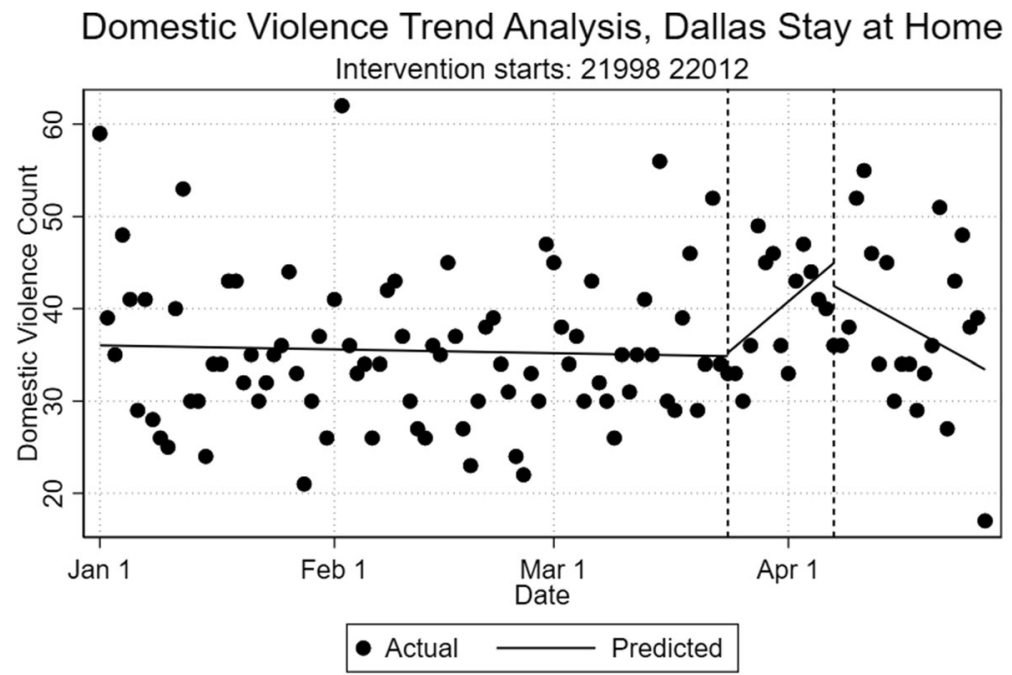

Prais-Winsten and Cochrane-Orcutt regression - $\operatorname{lag}(1)$

Fig. 3 Trend analysis, March 24th (21998) and April 7th (22012) breakpoints. Domestic violence trend analysis for before and after the stay-at-home order. Solid black lines represent the estimated trend and solid black points are observed data. The dashed vertical lines are at March 24th and April 7th, or 21,998 and 22,012 days post January 1st, 1960 
Table 3 Dickey-fuller test results

\begin{tabular}{lll}
\hline & Test statistic & MacKinnon $p$ value \\
Domestic violence & -8.51 & 0.00 \\
Critical Values: $1 \%=-3.504 ; 5 \%=-2.889 ; 10 \%=-2.579$ & \\
Number of Observations: 117 & & \\
\hline
\end{tabular}

However, if we consider the possibility that there are two changes in the trend of domestic violence, which might be observed visually in Fig. 1 and Fig. 2, then we can estimate a second break in the trend on April 7th (SAS date 22,012), 2 weeks after the stay-at-home order went into effect. Figure 3 contains the visual representation of the two break point estimation in Table 2. According to the results of the two break point trend analysis, there is statistically significant evidence that the trend in domestic violence changed twice: it increased after March 24th and decreased after April 7th.

\section{OLS and Poisson Regression Results}

Results of a Dickey-Fuller test in Table 3 suggest the domestic violence series is stationary, but the autocorrelation plot in Fig. 4 suggests the potential for some seasonality in the data, with the first, seventh, and fourteenth lag of domestic violence counts possibly exhibiting effects on future values. This presents the possibility that those past values in the series could be strong predictors of respective future values (e.g., domestic violence the day/week/

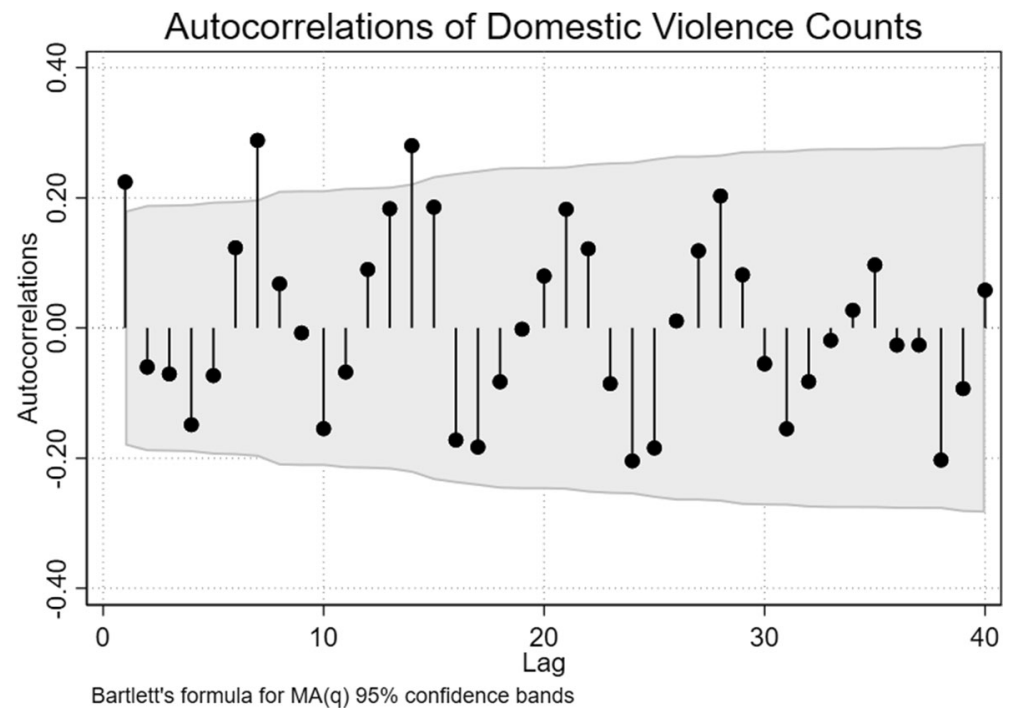

Fig. 4 Autocorrelation plot (correlogram). Autocorrelation plot of the lag terms with the data series. The shaded grey area is a $95 \%$ confidence interval band. If autocorrelation between a lag term and the data series extends above (positive) or below (negative) the confidence interval, there is a correlation between the lag term and the data series (ex: the first lag can help predict current data points) 
2 weeks before any given day is a good predictor of domestic violence on that given day). As shown in eqs. 1 through 8, we take into account the effects of the lagged series in both the OLS and Poisson models. These models take the following form:

\section{OLS}

$$
\text { Domestic Violence }=\alpha+\beta \times(\text { Stay }- \text { at }- \text { Home })+\varepsilon
$$

Domestic Violence $=\alpha+\beta_{1} \times($ Stay - at - Home $)+\beta_{2} \times \operatorname{lag} 1($ Domestic Violence $)+\varepsilon$

Domestic Violence $=\alpha+\beta_{1} \times($ Stay - at - Home $)+\beta_{2} \times \operatorname{lag} 7($ Domestic Violence $)+\varepsilon$

Domestic Violence $=\alpha+\beta_{1} \times($ Stay-at-Home $)+\beta_{2} \times \operatorname{lag} 14($ Domestic Violence $)+\varepsilon$

\section{Poisson}

$$
\ln (\text { Domestic Violence })=\alpha+\beta \times(\text { Stay }- \text { at }- \text { Home })+\varepsilon
$$

$\ln ($ Domestic Violence $)=\alpha+\beta_{1} \times($ Stay-at-Home $)+\beta_{2} \times \operatorname{lag} 1($ Domestic Violence $)+\varepsilon(6)$

$\ln ($ Domestic Violence $)=\alpha+\beta_{1} \times($ Stay - at - Home $)+\beta_{2} \times \operatorname{lag} 7($ Domestic Violence $)+\varepsilon(7)$

$\ln ($ Domestic Violence $)=\alpha+\beta_{1} \times($ Stay - at - Home $)+\beta_{2} \times \operatorname{lag} 14($ Domestic Violence $\left.)+\& 8\right)$

The results of our regression analyses in Table 4 provide evidence that domestic violence increased in the days after the stay-at-home order went into effect. Model 1 can be interpreted similar to a difference in means test, with days after the stay-at-home intervention regulations were implemented having an estimated 3.4 more domestic violence incidents, increasing from 35.4 to 38.8 . The stay-at-home intervention is statistically significant at the .10 level for Model 2 and 3, but not so in Model 4. Accounting for the effect of lagged values reduces the strength of the relationship between the stay-at-home order and the domestic violence series.

Our Poisson regression models are not affected in the same way as the OLS models when modeling the lagged dependent variable. Across Models 5-8, the stay-at-home order remains statistically significant at the .05 level. Poisson regression coefficients can be interpreted as the expected change in the difference in the natural log of expected 
domestic violence counts (Bruin, 2006). If we take Model 5 as an example, we can work to estimate the expected percent increase and expected change in domestic violence counts after the stay-at-home order was issued by doing the following:

$$
e^{\text {coefficient }}-1=\text { expected percent change }
$$

$$
e^{0.092}-1=\text { expected } 9.6 \% \text { increase }
$$

$e^{\text {coefficient }} \times e^{\text {constant }}=$ expected daily count after stay-at-home

$$
e^{0.092} \times e^{3.566}=\text { expected } 38.8 \text { domestic violence incidents }
$$

Even when accounting for potential seasonality, the results of Models 6-8 suggest we should expect anywhere from a 7.1 to $8.4 \%$ increase in domestic violence counts in the days after the stay-at-home order was issued.

\section{ARIMA Forecasting Model}

Finally, we turn to the results of the ARIMA forecast model displayed in Fig. 5. After fitting an ARIMA model suggested by the auto.arima() function in $\mathrm{R}^{8}$ to the data from the 83 days before stay-at-home order, we generated a predicted domestic violence count and two prediction intervals for the remaining 35 days. The 80 and $95 \%$ prediction intervals can be interpreted as containing the range of values of domestic violence counts we would expect to see 80 or $95 \%$ of the time based on the data prior to March 24th. We are most concerned with observed crime counts peaking above the upper bounds of the prediction intervals. Such increases essentially indicate a "spike" in crime counts as they go further beyond what we expect to see $95 \%$ of the time.

In the first week after the stay-at-home order went into effect, we see that the series rises above the $80 \%$ prediction interval for 3 days, peaks above the $95 \%$ interval 2 weeks afterwards, and once again rises above the upper bound of the $80 \%$ interval in the last week of our data. Overall $77 \%$ (27/35) observed days fall below the $80 \%$ interval, with only 1 day (2.8\%) rising above the $95 \%$ prediction interval's upper limit. This suggests one could have predicted this movement in crime before the stay-at-home order was put into place and that an upward trend after March 24th may have been part of an already upward moving average. ${ }^{9}$

\footnotetext{
${ }^{8}$ An ARIMA model with order $(0,0,2)$ was fit.

${ }^{9}$ In one interesting study using calls-for-service data to 15 large U.S. cities, Leslie and Wilson (2020) found a $10 \%$ increase in domestic violence callas accompanying the response to COIVD-19. Interestingly however, they also found that the increases in calls predated official stay-at-home orders and seems to have been due in large part to "households without a prior history of domestic violence" (p.1)
} 
Table 4 OLS and poisson regression results

\begin{tabular}{|c|c|c|c|}
\hline \multicolumn{2}{|c|}{ OLS regression models } & \multirow{2}{*}{$\begin{array}{c}\text { Coefficient } \\
3.40\end{array}$} & \multirow{2}{*}{$\frac{\text { Std error }}{1.64 * *}$} \\
\hline Model 1 & Shelter in place order & & \\
\hline & Constant & 35.37 & $0.89 * * *$ \\
\hline & R-squared $=0.356 ;(n=118)$ & & \\
\hline \multirow[t]{4}{*}{ Model 2} & First lag(DV) & 0.20 & $0.09 * *$ \\
\hline & Shelter in place order & 2.91 & $1.60 *$ \\
\hline & Constant & 28.01 & $3.34 * * *$ \\
\hline & R-squared $=0.0834 ;(n=117)$ & & \\
\hline \multirow[t]{4}{*}{ Model 3} & Seventh lag(DV) & 0.29 & $0.09 * * *$ \\
\hline & Shelter in place order & 2.95 & $1.59 *$ \\
\hline & Constant & 24.67 & $3.37 * * *$ \\
\hline & R-squared $=0.1307 ;(n=111)$ & & \\
\hline \multirow[t]{4}{*}{ Model 4} & Fourteenth lag(DV) & 0.29 & $0.09 * * *$ \\
\hline & Shelter in place order & 2.54 & 1.61 \\
\hline & Constant & 24.99 & $3.38 * * *$ \\
\hline & R-squared $=0.1320 ;(n=104)$ & & \\
\hline \multicolumn{4}{|c|}{ Poisson regression models } \\
\hline \multirow[t]{3}{*}{ Model 5} & Shelter in place order & 0.092 & $0.03 * * *$ \\
\hline & Constant & 3.566 & $0.02 * * *$ \\
\hline & Pseudo R-squared =0.0090; $(\mathrm{n}=118)$ & & \\
\hline \multirow[t]{4}{*}{ Model 6} & First lag(DV) & 0.01 & $0.00 * * *$ \\
\hline & Shelter in place order & 0.08 & $0.03 * *$ \\
\hline & Constant & 3.36 & $0.07 * * *$ \\
\hline & Pseudo R-squared =0.0204; $(\mathrm{n}=117)$ & & \\
\hline \multirow[t]{4}{*}{ Model 7} & Seventh lag(DV) & 0.01 & $0.00 * * *$ \\
\hline & Shelter in place order & 0.08 & $0.03 * *$ \\
\hline & Constant & 3.27 & $0.07 * * *$ \\
\hline & Pseudo R-squared =0.0324; $(\mathrm{n}=111)$ & & \\
\hline \multirow[t]{4}{*}{ Model 8} & Fourteenth lag(DV) & 0.01 & $0.00 * * *$ \\
\hline & Shelter in place order & 0.07 & $0.04 * *$ \\
\hline & Constant & 3.28 & $0.07 * * *$ \\
\hline & Pseudo R-squared =0.0318; $(n=104)$ & & \\
\hline
\end{tabular}

\section{Conclusions}

The coronavirus has wreaked havoc on the lives of persons worldwide. Numbers of infected cases and deaths change by the hour such that even listing a current number here would be immediately outdated. As scientists and doctors race for both treatments and vaccines, the ancillary effects of the COVID-19 epidemic are far-reaching. In this study, we were concerned with one of these additional outcomes, lockdowns or stay-athome orders, and the extent to which such orders would result in an increase in 
Domestic Violence Projection in Dallas, TX

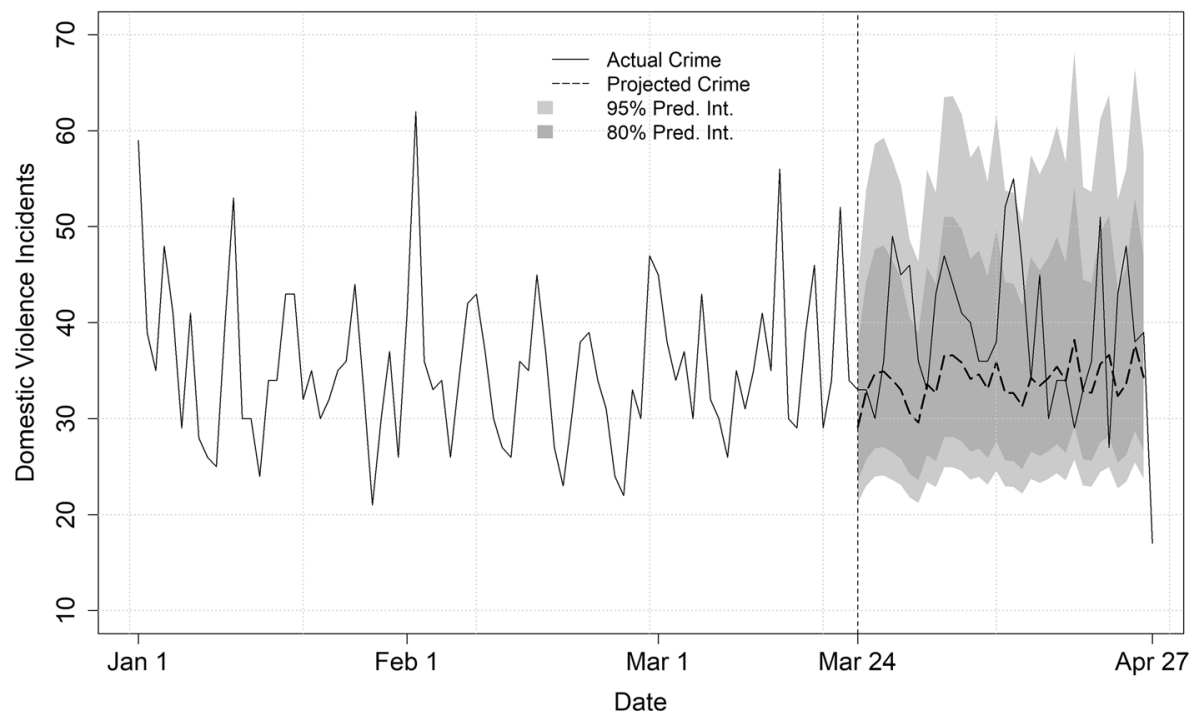

Fig. 5 Domestic violence projection. Domestic violence ARIMA forecast for daily incident counts in Dallas, TX. Observed crime data is the solid black line, and the dashed black line represents the forecasted point estimate for domestic violence. The dark grey polygon is the $80 \%$ prediction interval and the light grey polygon is the $95 \%$ prediction interval. The dotted black line at March 24th represents the beginning of the stay-at-home intervention

domestic violence. We examined this issue within the context of an intervention timeseries methodology using data from Dallas, Texas to compare domestic violence crimes for an 83-day period before the stay-at-home order was mandated to a 35-day period thereafter.

At first glance, we did not detect strong evidence of any change in the trend of domestic violence. However, upon further inspection of the time series, our results showed that there appeared to be an increase in domestic violence in the first 2 weeks after the stay-at-home order was implemented but then a decrease thereafter. Yet, some of that short-term spike seems to be associated with what appears to be an upward trend of domestic violence crimes that was already occurring prior to the stay-at-home order - leading us to cautiously interpret our regression models. While it may be true that domestic violence is higher (on average) after March 24 than before, it is difficult to directly and solely attribute the higher average count of incidents to the stay-at-home order. The latter finding of a short-term increase could be due to the fact that people were already voluntarily starting to stay at home in the days prior to the March 24 order because of CDC and public health officials warning of the dangers of this new virus and because of City, County, and State orders to limit social gatherings to less than 10 people. This interpretation also coincides with COVID-19 altering the routine activities of individuals. Let us explain a bit further.

On this point, Google created community mobility maps for counties and states in the U.S. and countries throughout the world that show the significant changes that the virus and its related consequences have had on the daily routines of people's lives. 
Google uses local history (turned on) data to track how often and for how long people travel to different location types, compared with a baseline value (the median value for the same day of the week, in this case, in January and early February). Figure 6 plots the Google Mobility data for Dallas County from February 15, 2020 through April 11, 2020 (the last data available), superimposed with the stay-at-home order issued on March 24, 2020. Through April 11, the percentage change from baseline is staggering: retail/recreation down $47 \%$, grocery/pharmacy down $14 \%$, workplace down $42 \%$, parks down $56 \%$, and transit stations down $48 \%$. The only exception to the downward trends, of course, is residential placement which increased $18 \%$ since the baseline but was increasing about a week prior as restaurants, bars, private clubs and other business started to suspend operations due to a Dallas County's order on March 16 (see Appendix). As can be discerned, changes in person's daily routines were already in motion well before the March 24 stay-at-home order.

In short, and based on the projection models, we do not see, at least with the data we have, any lasting increase or sustained higher levels of domestic violence. There is some evidence to reject the null hypothesis that the lockdowns had no (increasing) effect on domestic violence, but not all of the results strongly support the idea that the stay-at-home intervention has domestic violence increasing/at sustained higher levels. This of course, does not indicate the stay-at-home order was the sole cause of that short-term spike, which as we noted earlier may have also been the continuation of an already increasing time series, perhaps due to the seriousness of warnings about COVID-19 from other locales. That increase could also have been associated with other things going on at the same time such as people working more from home, being furloughed, or laid-off from their employer. As previously noted, financial stress and problems at work have been linked to perpetration of partner abuse (Capaldi et al., 2012) and these stresses brought on by the COVID-10 pandemic could be related to the increase in domestic violence prior to the stay-at-home order.

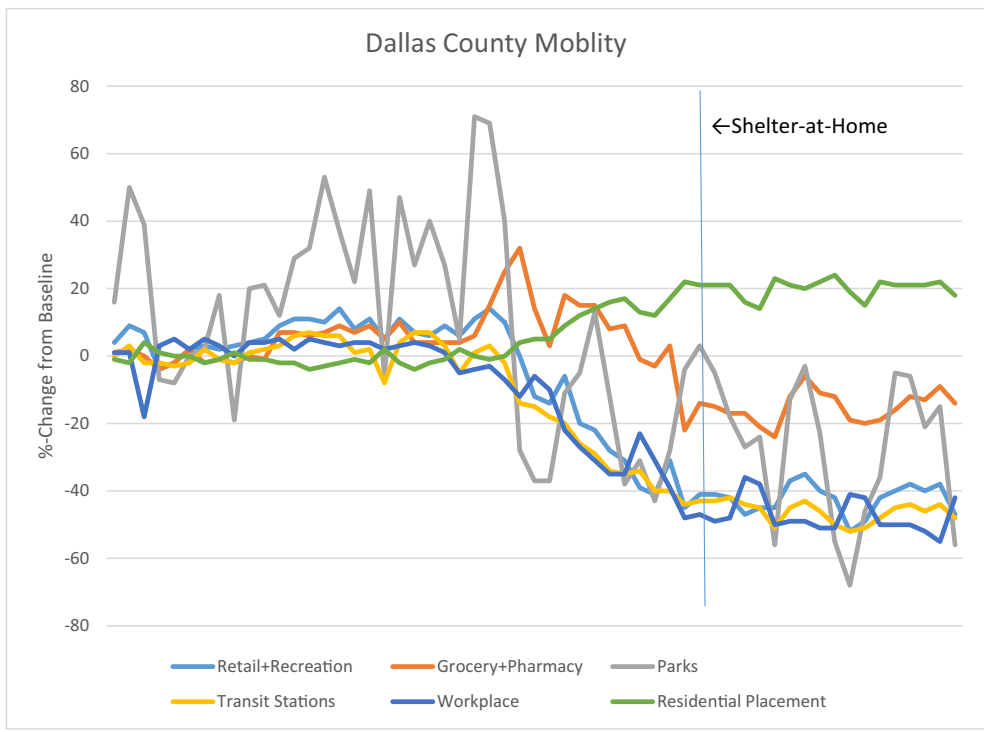

Fig. 6 Google mobility patterns, Dallas County, Dallas, Texas. February 29, 2020-April 11, 2020 
We believe that our analyses offer an important, strong empirical baseline for which additional data from Dallas could be collected to assess the more long-term effects of the stay-at-home order with respect to domestic violence as well as other crime types. Yet, we are also mindful of the limitations of our work. First, while we had longer follow-up data than most studies to date, there is a need to consider additional data to see what happens when other restrictions are loosened or lifted altogether. Second, while we focused on crime counts, there is also a need to perform a deep dive into the data to examine if there are chronic abusers that were committing more of the offenses - as is the case with what has been learned from criminal career research (Piquero, Farrington, and Blumstein, 2003). Third, using a large city like Dallas for our case study may pose some generalizability concerns, especially with respect to the problem of domestic violence in rural communities. On this score, it is important to note that many rural communities in Texas did not experience any sheltering orders, but analysis of domestic violence across different types of communities, city, suburban, and rural is important going forward. Finally, we relied on official records and have surely missed out on other domestic incidents that did not come to the attention of the police department, which we suspect is a larger-but uncertain number.

Like crime, we will likely be living with COVID-19 for the rest of our lifetimes. It is incumbent on the community of scholars to continue to track its adverse effects on persons and their lives throughout the world.

\section{Appendix A: City of Dallas, Dallas County, State of Texas Regulations and Orders Regarding COVID-19}

\section{City of Dallas (Mayor Eric Johnson)}

\section{March 12, 2020}

- Mayor declared a state of local disaster for the City of Dallas resulting from the COVID-19 Pandemic

\section{March 16, 2020 [Emergency regulations]}

\section{- Section 1 - Prohibited and limited gatherings}

- Public or private community gatherings are prohibited anywhere in the City of Dallas

- Restaurant, microbrewery, micro-distillery or winery may only provide take out delivery or drive-through services as allowable by law

- Bar, lounge, or tavern; private club; personal services use for gym or health studio; inside commercial amusement; or theater shall close. 
- Section 2 - Reporting of COVID-19 tests

○ All public, private, and commercial laboratories operating within the City of Dallas and performing COVID-19 testing shall report (a) the number of tests performed and (b) the number of positive cases by 5:00 PM each day for the prior 24-h period

- Section 3 - Definitions

- Community gathering is any indoor or outdoor event or convening that brings together or is likely to bring together 50 or more persons at the same time in a single room or other confined or enclosed space (such as an auditorium, stadium, arena or event center, meeting hall, conference center, large cafeteria or any other confined indoor or confined outdoor space).

- Outdoor gathering is limited to events in confined outdoor spaces, which means an outdoor space that is enclosed by a fence, physical barrier or other structure and where people are present and they are within $6 \mathrm{ft}$ of one another for extended periods.

○ Community gathering does not include:

- Spaces where 50 or more persons may be in transit or waiting for transit (such as airports, bus stations or terminals)

- Office space, public and private schools, child-care facilities, residential buildings or any type of temporary sheltering or housing

- Grocery stores, shopping malls or other retail establishments where large numbers of people are present but it is unusual for them to be within $6 \mathrm{ft}$ of one another for extended periods

- Hospitals and medical facilities

- Section 4 - Posting of these regulations

- Section 5 - Severability

- Section 6 - Effective date

○ To take effect immediately except for Section 1 and 3 which go into effect at 11:59 PM on March 16

- Section 7 - Suspension and modification of ordinances

- Section 8 - Penalties

$\circ$ Emergency regulations have the effect of an ordinance

- Upon conviction punishable by a fine of not less than $\$ 50$ and not more than $\$ 2000$

\section{March 19, 2020}

- The state of local disaster was extended to April 29, 2020 


\section{March 24, 2020 [Seconded Amended Emergency Regulations]}

- Section 1 - Adoption of county orders

- The amended order of County Judge Clay Jenkins, dated March 23, 2020, is adopted in the City of Dallas

- Regulations take effect on March 24, 2020 not March 23, 2020

- Any reference to the geographic area of Dallas County shall instead mean the City of Dallas

- Any section that specifically addresses Dallas County governmental functions are excepted

- Section 2: Reporting of COVID-19 cases

- Section 3: Posting of these regulations

- Section 4: Suspension and modification of ordinances

- Section 5: City council meetings

- Beginning March 26, 2020 all meetings must be conducted virtually.

- Section 6: Prohibition of council committee meetings

- Standing and ad hoc meetings are cancelled except for those dealing with COVID-19

- Section 7: Severability

- Section 8: Savings clause

- All ordinances of the City of Dallas and the Dallas City Code, as amended, shall remain in full force and effect, save and except as amended by this emergency regulation.

- Section 9: Penalties

- Section 10: Effective date

- To take effect immediately upon issuance. Shall continue until regulations are rescinded, superseded or amended or until the expiration.

\section{March 30, 2020 [Third Amended Emergency Regulations]}

- Section 1 - Adoption of county order

- Section 2 - Adoption of Dallas County order regarding long-term care facilities 
- The order of County Judge Clay Jenkins regarding long-term health care facilities, dated March 29, 2020, is adopted in the City of Dallas

- Any reference to the geographic area of Dallas County shall instead mean the City of Dallas

- Any section that specifically addresses Dallas County governmental functions are excepted

- Section 3 - Adoption of Dallas County Stay Home Say Safe rules for the construction industry

- The Stay Safe Stay Home Rules for the construction industry of Dallas County Judge Clay Jenkins is adopted to the City of Dallas.

- Section 4 - Reporting of COVID-19 tests

- Section 5 - Hospitals

○ All hospitals in the City of Dallas shall report each day at 4:00 PM the total number of (1) patient beds and patient beds occupied (2) ICU patient beds and ICU patient beds occupied (3) ventilators that are available and ventilators being used by patients

- Section 6 - Posting of these regulations

- Section 7 - Suspension and modification of ordinances

- Section 8 - City council meetings

- Section 9 - Prohibiting certain council committee meetings

- Section 10 - Prohibiting certain city board and commission meetings

○ All city boards and commissions are prohibited from meeting through April 29, 2020

- Except the following can meet by telephone or videoconferencing; city planning commission, park and recreation board, other boards and commissions dealing with compliance to state or federal law

- Section 11 - Severability

- Section 12 - Savings clause

- Section 13 - Penalties

- Section 14 - Effective date

- To take effect immediately upon issuance. Shall continue until regulations are rescinded, superseded or amended or until the expiration.

Source: https://dallascityhall.com/Pages/coronavirus-media-releases.aspx (accessed April 28, 2020). 


\section{Dallas County (Judge Clay Jenkins)}

March 12, 2020

- Judge declares a local state of disaster for public health emergency for Dallas County

- Judge orders regarding community gatherings

○ Effective: 11:00 AM March 13 until 11:00 AM March 20

- Prohibits public or private community gatherings of over 500 people

- Strongly recommends canceling, rescheduling or not attending events with more than 250 people

- Strongly urges organizations that serve high-risk populations to cancel gatherings of more than 10 people

\section{March 15, 2020 County cancels all jury trials through May 8, 2020}

\section{March 16, 2020 - Amended Order}

Note: President Trump acknowledged the gravity of the COVID-19 pandemic and released guidelines that limits people's interactions and recommended avoiding groups of more than 10

- Effective: 11:59 PM March 16 until 11:00 AM March 20

- Public or private community gatherings are prohibited

- Restaurants with or without drive-in or drive-through services and microbreweries, microdistilleries, or wineries may only provide take out, delivery, or drive-through services

- Bars, loungers, taverns or arcades and private clubs shall close

\section{March 18, 2020 - Amended Order}

- Effective: 11:59 PM March 18 until 11:00 AM March 20

- Public or private recreational gatherings and community gatherings are prohibited. Amended order distinguishes between community and recreational gatherings as defined below.

- Community gatherings are limited to 50 people and include weddings, religious services, funerals and other gatherings that will bring together $50+$ persons at the same time in a single room, confined or enclosed space.

- Recreational gatherings are limited to 10 people and can be indoor or outdoor events that are primarily social or recreational in nature such as parties, backyard barbecues, social events, sporting events or other such gatherings. 
- Dallas County Tax Offices and passport offices shall close for in-person services

- Suspends all delivery hour restrictions for transport to or from any entity involved in the selling or distribution of food products, medicine, or medical supplies for next 60 days

- Advises Justices of Peace to suspend eviction hearings and writs of possession for at least the next 60 days to prevent renters from being displaced

- Clarifies that all gyms are to close

- Adds farmers markets to the definition of food suppliers

\section{March 21, 2020 - Amended Order}

- Effective: 11:59 PM March 21 until 11:59 PM April 3

- Bars, lounges, taverns, private clubs, arcades, bowling alleys, theaters, gyms, fitness centers, gymnastic studios and martial arts studios shall close

- Massage parlors, nail salons, hair salons, barber shops, beauty salons, hair removal services, spas, tattoo and piercing parlors, and all other non-medical, personal care services that cannot be provided while maintaining $6 \mathrm{ft}$ of distance shall close.

- All elective medical, surgical, and dental procedures are prohibited. Hospitals, ambulatory surgery centers, dental offices, and other medical facilities are directed to identify procedures that are deemed "elective" by assessing which procedures can be postponed or cancelled based on patient risk considering the emergency need for redirection of resources to COVID-19

\section{March 24, 2020 - Stay at Home Order}

NOTE: World Health Organization indicated the US has the potential to become the center of COVID-19 pandemic.

- Effective: 9:00 Pм March 24 until 11:59 PM April 3

- All individuals living within Dallas County are ordered to shelter at their place of residence. To the extent individuals are using shared outdoor spaces, they must main proper social distancing of at least $6 \mathrm{ft}$ from any other person when outside their residence. All persons may leave their residences for only essential activities or to provide or perform essential governmental functions or to operate essential businesses.

- All businesses operating in the county (except for essential businesses) are required to cease all activities at facilities located within the county. Businesses may continue to operate if employees and contractors can work from their own residences. To the extent possible, essential businesses should maintain social distancing of $6 \mathrm{ft}$ between employees and the general public.

- Religious and worship services may only be provided by video and teleconference. Religious institutions must limit in-person staff to 10 people or less when preparing video or teleconference services and must follow $6 \mathrm{ft}$ social distancing 


\section{March 29, 2020 - Amended Order}

- Effective: 11:59 pM March 29 until 11:59 PM April 3

- Clarified residences to include hotels, motels, shared rentals and similar facilities.

- Added and clarified "minimum basic operations"

- Added and defined "essential travel" language

- Added safety provisions for contractors

- Added prohibition on price gouging

- Re-formatted the order

\section{March 31, 2020 - Amended Order}

- Effective 11:59 PM March 31 until 11:59 PM April 3

- All public, private, and commercial laboratories operating within Dallas County and performing COVID-19 testing shall report by 5:00 PM each day for the prior 24-h period: the number of COVID-19 tests performed and the number of positive tests

\section{April 2, 2020 - Amended Order}

- Effective: 11:59 PM April 3 until 11:59 PM April 3

- Adds safety rules for manufacturers and distributors

- Caps late fees for rent at $\$ 15 /$ month

- Requires employees of essential business to telecommute when possible

- Prohibits employers from requiring negative COVID-19 test of physician note before going back to work

- Clarifies that limits on purchases of toilet paper and other essential items do not apply to Essential Businesses and Government Offices

\section{April 3, 2020 - Amended Order}

- Effective: 11:10 Am April 3 until 11:59 pm April 30

- Extended 'Stay at Home' order through April 30, 2020.

April 3, 2020 Order: Continuance of Declaration of Local Disaster for Public Health Emergency

- Extended until 11:59 PM May 20 
April 6, 2020 - Amended Order

- Effective: 11:59 PM April 6 until 11:59 PM April 30

- Adds rules for financial institutions and realtors for conducting business in Dallas county

- Adds rules for common carriers, delivery services, and related companies

\section{April 8, 2020 - Amended Order}

- Effective 11:59 April 8 until 11:59 April 30

- Places restrictions on short-term rentals

- Prohibits door-to-door solicitation

\section{April 16, 2020 - Amended Order}

- Effective: 1:00 PM April 16 until 11:59 PM April 30

- Covering of nose and mouth

- Everyone over the age of two shall wear some form of covering over their nose and mouth when patronizing an essential business or using public transportation

○ County Sheriff's office, County Fire Marshal's office and other peace officers are authorized to enforce this order

- Violation is punishable by a fine not to exceed $\$ 1000$ and/or confinement in jail for a term not to exceed 180 days

\section{April 17, 2020 - Amended Order}

- Effective: 11:59 PM April 17 until 11:59 PM April 30

- Allows stores that sell fabric to operate for the sole purpose of selling school supplies and fabric and other supplies needed to make cloth coverings and masks

- Adds language that the failure to wear a cloth covering cannot result in any civil or criminal fines or penalties

\section{April 18, 2020 - Amended Order}

- Effective: 3:00 PM April 18 until 11:59 PM April 30

- Updated to mirror cloth covering enforcement language from the Commission's Court order regarding craft stores and facial covering. 
- No substantive changes were made to the order

\section{April 23, 2020 - Amended Order}

- Effective: 12:00 pm April 23 until 11:59 PM May 15

- Extends the order until May 15, 2020

- Removes elective surgery language to be consistent with Governor's order

- Adds language on "reopened services" to be consistent with Governor's order and includes visiting "reopened services" as an allowable activity

- Updates language on religious and worship services to be consistent with Governor's order

- Allows auto dealers showrooms to be open

- Requires schools to be closed for the remainder of the 2019-2020 school year to be consistent with Governor's order

- Exempts CARE Act payments from garnishment, except for child support payments

Source: https://www.dallascounty.org/covid-19/ (accessed April 28, 2020).

\section{State of Texas (Governor Greg Abbott)}

March 13, 2020

- Governor declared a state of disaster for all counties in Texas because of the COVID-19 Pandemic.

- Authorizes the use of all available resources of state government and of political subdivisions that are reasonable necessary to cope with the disaster.

- Any regulatory statute prescribing the procedures for conduct of state business or any order or rule of a state agency that would in any way prevent, hinder, or delay necessary action in coping with this disaster shall be suspended upon written approval of the Office of the Governor.

March 19, 2020

- The Commissioner of the Department of State Health Services (John W. Hellerstedt, M.D.) declared a state of public health disaster for the entire state of Texas.

o The following actions should be taken immediately. 
- People, businesses, and communities should immediately undertake hygiene, cleanliness and sanitation practices that are accessible, affordable and known to be effective against COVID-19.

- Wash hands often for $20 \mathrm{~s}$; if no soap and water than use hand sanitize with at least $60 \%$ alcohol.

- Cover coughs and sneezes.

- Avoid touching your eyes, nose, and mouth with unwashed hands.

- Disinfect surfaces, buttons, handles, knobs and other places touched often.

- Avoid close contact with people who are sick.

- People who are known to have or are under investigation or monitoring should adhere to the directions provided to hem by public health officials.

- People who are ill should isolate themselves at home until they recover.

- Limit trips into the public to essential outings - traveling to work, the grocery store, the pharmacy or to seek medical care.

- Limit as much as possible close contact with other people. Stay $6 \mathrm{ft}$ away.

- Do not gather in social groups of more than 10 individuals.

- Employers should allow work at home alternatives to the greatest extent possible.

- Restaurants should not allow dine-in options, either inside or outside Takeout and curbside options with minimal contact are permitted and highly encouraged.

- Governor orders the following to mitigate COVID-19 spread [Executive Order 8]

- Effective 11:59 PM March 20 until April 3.

- Order 1 - In accordance with the Guidelines from the President and the CDC, every person in Texas shall avoid social gatherings of more than 10 people.

o Order 2 - In accordance with the Guidelines from the President and the CDC, people shall avoid eating or drinking at bars, restaurants, and food courts, or visiting gyms or massage parlors; provided, however that the use of drive-thru, pickup, or delivery options is allowed and highly encouraged throughout the limited duration of this executive order.

o Order 3 - In accordance with the Guidelines from the President and the CDC, people shall not visit nursing homes or retirement or long-term facilities unless to provide critical assistance.

o Order 4 - In accordance with the Guidelines from the President and the CDC, schools shall temporarily close.

○ Does not prohibit people from visiting grocery stores, gas stations, parks, and banks, so long as the necessary precautions are maintained to reduce the transmission of COVID-19.

$\circ$ Does not mandate sheltering in place.

- All critical infrastructure will remain operational, domestic travel will remain unrestricted, and government entities and businesses will continue providing essential services.

○ For offices and workplaces that remain open, employees should practice good hygiene and where feasible work from home in order to achieve optimum isolation from COVID-19. 
March 22, 2020

- Governor orders the following to increase hospital bed capacity [Executive Order 9]

- Effective: Immediately until 11:59 PM April 21

- Failure to comply: punishable by a fine not to exceed $\$ 1000$, confinement in jail for a term not to exceed 180 days, or both fine and confinement.

○ To expand hospital bed capacity

- All surgeries and procedures that are not immediately medically necessary to correct a serious medical condition of, or to preserve the life of, a patient who without immediate performance of the surgery or procedure would be at risk for serious adverse medical consequences such as death shall be postponed.

- Created a temporary Supply Chain Strike Force tasked with guiding collaboration between public and private sectors to ensure health care facilities have the supplies and resources they need to respond to COVID-19.

March 24, 2020

- Governor orders the following on COVID-19 reporting [Executive Order 10]

○ Effective 11:59 PM March 24

- All hospitals in TX shall submit to DSHS daily reports of hospital bed capacity, in the manner prescribed by DSHS who will promptly share the information with the CDC.

- Every public or private entity utilizing an FDA-approved test for human diagnostic purposes of COVID-19 shall submit to DSHS as well as to the local health department, daily reports of all tests, both positive and negative. DSHS will promptly share this information with the CDC.

\section{March 26, 2020}

- Governor orders the following to mandate quarantine for certain air travelers [Executive Order 11]

- Effective 12:00 PM March 28

- Failure to comply: punishable by a fine not to exceed $\$ 1000$, confinement in jail for a term not to exceed 180 days, or both fine and confinement.

$\circ$ Every person who enters TX as the final destination through an airport from a point of origin or last departure in NY, NJ, CT, or the City of New Orleans shall be subject to mandatory self-quarantine for a period of 14days from the time of entry or the duration of the person's presence in TX, whichever is shorter. 
- All persons are responsible for all associated costs, including transportation, lodging, food, and medical care.

- A form prescribed by TX Department of Public Safety will be used to designate a quarantine location (residence or hotel), and provide full name, date of birth, home address, telephone number, and driver license or passport information.

Does not apply to people traveling in connection with military service, emergency response, health response, or critical-infrastructure functions.

\section{March 29, 2020}

- Governor orders the following to mandate quarantine for certain road travelers [Executive Order 12]

- Effective 12:00 PM March 30

- Failure to comply: punishable by a fine not to exceed $\$ 1000$, confinement in jail for a term not to exceed 180 days, or both fine and confinement.

$\circ$ Every person who enters TX through roadways from LA shall be subject to mandatory self-quarantine for a period of 14-days from the time of entry or the duration of the person's presence in TX, whichever is shorter.

- All persons are responsible for all associated costs, including transportation, lodging, food, and medical care.

- A form prescribed by TX Department of Public Safety will be used to designate a quarantine location (residence or hotel), and provide full name, date of birth, home address, telephone number, and driver license or passport information.

Does not apply to people traveling in connection with military service, emergency response, health response, or critical-infrastructure functions.

- Governor orders the following relating to county and municipal jail detention [Executive Order 13]

- Effective: Immediately.

- To create a statewide standard to avoid disparate release policies/practices that may endanger the public safety of TX.

$\circ$ Article 17.03 Suspend statues and rules relating to personal bond to the extent necessary to preclude the release of personal bond of any person previously convicted of a crime that involves physical violence or threat of physical violence or of any person currently arrested for such a crime that is supported by probable cause.

- Orders no authority should release on personal bond any person previously convicted of a crime that involves physical violence or the threat of physical 
violence, or any person currently arrest for such a crime that is supported by probable cause.

- Article 17.151 suspended to the extent necessary to prevent any person's automatic release on personal bond because the State is not ready for trial.

$\circ$ Article 15.21 suspended to prevent any person's automatic release on personal bond because the jail of the county where the offense is alleged to have been committed does not take charge of the arrested person before the 11th day after the date the person is committed to the jail.

- Article 42.032 suspended to the extent necessary to preclude the grant of commutation of time for good conduct, industry, and obedience to achieve the release of any person who has previously been convicted of or is currently serving a sentence for a crime that involves physical violence or the threat of physical violence.

- Orders no authority should grant the commutation of time for good conduct, industry, and obedience to achieve the release of any person who has previously been convicted or is currently serving a sentence for a crime that involves physical violence or the threat of physical violence.

○ Article 42.035 suspended to the extent necessary to preclude any release of a person to electronic monitoring program, rather than being confined in jail, if the person has been previously convicted of or is currently serving a sentence for a crime that involves physical violence or the threat of violence.

- Sections 418.1015(b) and 418.108 are suspended to the extent necessary to preclude any county judge or mayor or any emergency management director from releasing persons under any circumstances inconsistent with this order.

- Governor expands Executive Order 11 (through proclamation) for air travel quarantine

○ Adds the following:

- State of CA

- State of LA

- State of WA

- City of Atlanta, GA

- City of Chicago, IL

- City of Detroit, MI

- City of Miami, FL

\section{March 31, 2020}

- Governor orders the following on essential services [Executive Order 14]

○ Effective: 12:01 Am April 2 until April 30. 
$\circ$ Every person in TX shall, except when necessary to provide or obtain essential services, minimize social gatherings and minimize in-person contact with people who are not in the same household.

- Essential services shall consist of everything listed by the US Department of Homeland Security in its Guidance on the Essential Critical Infrastructure Workforce Version 2.0 plus religious services conducted in churches, congregations, and houses of worship.

- People should follow the Guidelines from the President and the CDC by practicing good hygiene, environmental cleanliness, and sanitation, implementing social distancing and working from home if possible.

- People shall avoid eating or drinking at bars, restaurants and food courts or visiting gyms, massage establishments, tattoo studios, piercing studios or cosmetology salons; however, the use of drive-thru, pickup or delivery options for food and drink is allowable and highly encouraged.

- Does not prohibit people from accessing essential services or engaging in essential daily activities such as going to the grocery store or gas station, providing or obtaining essential services, visiting parks, hunting or fishing or engaging in physical activity like jogging or bicycling so long as the necessary precautions are maintained to reduce the spread of COVID19.

○ People shall not visit nursing homes, state supported living centers, assisted living facilities, or long-term care facilities unless to provide critical assistance. Schools shall remain temporarily closed to in-person classroom attendance and shall not recommence before May 4, 2020.

\section{April 17, 2020}

- Governor loosens restrictions on surgeries [Executive Order 15]

○ Effective 11:59 PM April 21 until 11:59 PM May 8

$\circ$ All licensed heath care professionals shall postpone all surgeries and procedures that are not medically necessary to diagnose or correct a serious medical condition, or to preserve the life of, a patient who without the surgery or procedure would be at risk for adverse medical consequences. This prohibition shall not apply to either of the following:

- Any procedure that, if performed in accordance with commonly accepted standard of clinical practice, would not deplete the hospital capacity or the PPE needed to cope with COVID-19.

- Any surgery or procedure that has certified in writing to the TX Health and Human Services Commission both (1) that it will reserve at least $25 \%$ of its hospital capacity for treatment of COVID-19 patients and (2) that it will not request any PPE from any public source, whether federal, state, or local for the duration of the COVID-19 disaster. 
- Governor reopens select services [Executive Order 16]

$\circ$ Effective: immediately until April 30

$\circ$ Every person in TX shall, except where necessary to provide or obtain essential services or reopened services, minimize social gatherings and maximize inperson with people are not in the same household

$\circ$ Re-opened services shall consist of:

- Starting April 24, 2020 at 12:01

- Retail services that are not "essential services" but that may be provided through pickup, delivery by mail, or delivery to the customer's doorstep

- People should practice good hygiene, environmental cleanliness and sanitation, implement social distancing and work from home whenever possible

- Religious services should be conducted in accordance with the Guidelines for Houses of Worship During the COVID-19 crisis

o People shall avoid eating or drinking at bars, restaurants, and food courts, or visiting gyms, massage establishments, tattoo studies, piercing studios, or cosmetology salons

- However drive-thru, pickup or delivery options are highly encouraged

- Does not prohibit people from accessing essential or reopened services or essential activities such as going to the grocery store or gas station, visiting parks, hunting or fishing, or engaging in physical activity like jogging or bicycling so long as social distance is maintained

- People shall not visit nursing homes, state supported living centers, assisted living facilities, or long term care facilities unless to provide critical assistance

- Schools shall remain temporarily closed to in-person classroom attendance by students and shall not recommence before the end of the 2019-2020 school year

○ Order supersedes any conflicting order issued by local officials.

- Governor establishes a task force to open Texas [Executive Order 17]

o Created the Governor's Strike Force to Open Texas to advise the governor on safety and strategically restarting and revitalizing all aspects of the Lone Star State - work, school, entertainment, and culture.

Source: https://gov.texas.gov/coronavirus (accessed April 28, 2020).

\section{References}

Agnew, R. (1992). Foundation for a general strain theory of crime and delinquency. Criminology, 30, 47-87.

Agnew, R., Rebellon, C. J., \& Thaxton, S. (2000). A general strain theory approach to families and delinquency. In G. L. Fox \& M. L. Benson (Eds.), Families, crime, and criminal justice (pp. 113-138). New York: JAI Press, Inc..

Anda, R. F., Felitti, V. J., Bremner, J. D., Walker, J. D., Whitfield, C. H., Perry, B. D., et al. (2006). The enduring effects of abuse and related adverse experiences in childhood. European Archives of Psychiatry and Clinical Neuroscience, 256(3), 174-186. 
Ashby, M. P. J. (2020). Initial evidence on the relationship between the coronavirus pandemic and crime in the United States. Crime Science, 9, 6. https://doi.org/10.1186/s40163-020-00117-6 accessed May 27, 2020.

Associated Press (April 12, 2020). Crime drops around the world as Covid-19 keeps people inside. https:/apnews. com/bbb7adc88d3fa067c5c1b5c72a1a8aa6 (accessed May 1, 2020).

Bilyeau, N. (2020). https://thecrimereport.org/2020/04/07/covid-19-stokes-shadow-pandemic-of-violenceagainst-women-says-un-group/ (accessed April 7, 2020).

Black, D. A., Heyman, R. E., \& Slep, A. M. S. (2001). Risk factors for child physical abuse. Aggression and Violent Behavior, 6(2-3), 121-188.

Bruin, J. 2006. Newtest: Command to compute new test. UCLA: Statistical Consulting Group. Retrieved 4/30/ 2020 from https://stats.idre.ucla.edu/stata/ado/analysis/.

Campedelli, G. M., Aziani, A., \& Favarin, S. (2020). Exploring the effect of 2019-nCoV containment policies on crime: The case of Los Angeles. arXiv:2003.11021 [econ, q-fin, stat], arxiv 2003.11021. https://doi. org/10.31219/osf.io/gcpq8 (accessed April 30, 2020).

Capaldi, D. M., Knoble, N. B., Shortt, J. W., \& Kim, H. K. (2012). A systematic review of risk factors for intimate partner violence. Partner Abuse, 3(2), 231-280. https://doi.org/10.1891/1946-6560.3.2.231.

Currie, J., \& Tekin, E. (2012). Understanding the cycle childhood maltreatment and future crime. Journal of Human Resources, 47(2), 509-549.

CW39 (April 3, 2020). Houston COVID-19 update: Increased cases; domestic violence, assault, burglary also up. https://cw39.com/news/local/houston-covid-19-update-increased-cases-domestic-violence-assaultburglary-also-up/ (accessed April 5, 2020).

Fang, X., Brown, D. S., Florence, C. S., \& Mercy, J. A. (2012). The economic burden of child maltreatment in the United States and implications for prevention. Child Abuse \& Neglect, 36(2), 156-165.

Gonzalez, J. R. (March 30, 2020). Montgomery County's DA's office sees 35 percent increase in domestic violence cases during coronavirus isolation. https://www.yourconroenews. com/neighborhood/moco/news/article/Montgomery-County-DA-s-Office-sees-35-percent-15166757.php (accessed April 8, 2020).

Goodman, C. K. (4/29/2020). Mental health meltdown looms for South Florida, and coronavirus is the trigger. https://www.sun-sentinel.com/coronavirus/fl-ne-mental-health-meltdown-20200428-43wy4b6tu5ggfg4 uymkwmwl5my-story.html (accessed April 29, 2020).

Google LLC Google COVID-19 Community Mobility Reports. https:/www.google.com/covid19/mobility/ (accessed April 30, 2020).

Herrenkohl, T. I., Sousa, C., Tajima, E. A., Herrenkohl, R. C., \& Moylan, C. A. (2008). Intersection of child abuse and children's exposure to domestic violence. Trauma, Violence, \& Abuse, 9(2), 84-99. https://doi. org/10.1177/1524838008314797.

Hussey, J. M., Chang, J. J., \& Kotch, J. B. (2006). Child maltreatment in the United States: Prevalence, risk factors, and adolescent health consequences. Pediatrics, 118(3), 933-942.

Jackson, A. (April 10, 2020). A crisis mental-health hotline has seen an $891 \%$ spike in calls. https://www.cnn. com/2020/04/10/us/disaster-hotline-call-increase-wellness-trnd/index.html (accessed April 10, 2020).

Jonson-Reid, M., Chance, T., \& Drake, B. (2007). Risk of death among children reported for nonfatal maltreatment. Child Maltreatment, 12(1), 86-95.

Kamenetz, A. (April 28, 2020). Child sexual abuse reports are on the rise amid lockdown orders. NPR. https://www. npr.org/sections/coronavirus-live-updates/2020/04/28/847251985/child-sexual-abuse-reports-are-on-the-riseamid-lockdown-orders (accessed May 02, 2020).

Kim, H., Wildeman, C., Jonson-Reid, M., \& Drake, B. (2017). Lifetime prevalence of investigating child maltreatment among US children. American Journal of Public Health, 107(2), 274-280.

Lansford, J. E., Dodge, K. A., Pettit, G. S., Bates, J. E., Crozier, J., \& Kaplow, J. (2002). A 12-year prospective study of the long-term effects of early child physical maltreatment on psychological, behavioral, and academic problems in adolescence. Archives of Pediatrics \& Adolescent Medicine, 156(8), 824-830.

Leslie, E., \& Wilson, R. (2020). Sheltering in place and domestic violence: Evidence from calls for service during COVID-19 (May 14, 2020). Available at SSRN: https://ssm.com/abstract=3600646. Accessed May 27, 2020.

McCrory, E., De Brito, S. A., \& Viding, E. (2011). The impact of childhood maltreatment: A review of neurobiological and genetic factors. Frontiers in Psychiatry, 2, 48.

McKinnon, R. (April 29, 2020). Coronavirus Florida: With schools closed, child abuse reporting declines. https:/www.heraldtribune.com/news/20200426/coronavirus-florida-with-schools-closed-child-abusereporting-declines (accessed April 29, 2020).

Morris, M. C., Marco, M., Maguire-Jack, K., Kouros, C. D., Im, W., White, C., et al. (2019). County-level socioeconomic and crime risk factors for substantiated child abuse and neglect. Child Abuse \& Neglect, 90, 127-138. 
National Domestic Violence Hotline (n.d.). Warning signs of domestic violence. Retrieved April 7, 2020 from https://www.thehotline.org/is-this-abuse/abuse-defined/.

Neuman, S. (April 6, 2020). Global lockdowns resulting in 'horrifying surge' in domestic violence, U.N. warns. https:/www.npr.org/sections/coronavirus-live-updates/2020/04/06/827908402/global-lockdownsresulting-in-horrifying-surge-in-domestic-violence-u-n-warns (accessed April 6, 2020).

Ogle, C. (April 8, 2020). Is Miami buying more booze during coronavirus quarantine? We have the receipts. https://www.miamiherald.com/miami-com/miami-com-news/article241834566.html? (Accessed April 8, 2020).

Ovalle, D., \& Rabin, C. (April 9, 2020). Domestic violence cases drop in Miami during coronavirus. Is that the clam before the storm? https://www.miamiherald.com/news/local/crime/article241841711.html? (Accessed April 10, 2020).

Payne, J., Morgan, A., \& Piquero, A. R. (2020). Covid-19 and violent crime: A comparison of recorded offence rates and dynamic forecasts (ARIMA) for March 2020 in Queensland, Australia. https://t. co/GyyD8Y1TUp?amp=1 (accessed April 30, 2020).

Piquero, A. R., Farrington, D. P., \& Blumstein, A. (2003). The criminal career paradigm: Background and recent developments. In M. Tonry (Ed.), Crime and justice: A review of research (Vol. 30, pp. 359-506). Chicago: University of Chicago Press.

Piquero, A. R., Piquero, N. L., \& Riddell, J. R. (2019). Do (sex) crimes increase during the United States formula 1 grand prix? Journal of Experimental Criminology, forthcoming. https://doi.org/10.1007 /s11292-019-09398-7.

Shayegh, S., \& Malpede, M.(April 2, 2020). Staying home saves lives, really! Available at SSRN: https:// ssrn.com/abstract=3567394 or https://doi.org/10.2139/ssrn.3567394.

Solis, N., \& Martinez, G. (March 23, 2020). Cook children's sees spike in child abuse cases likely from COVID-19 stress. https:/www.fox4news.com/news/cook-childrens-sees-spike-in-child-abuse-caseslikely-from-covid-19-stress (accessed April 5, 2020).

Sousa, C., Mason, W. A., Herrenkohl, T. I., Prince, D., Herrenkohl, R. C., \& Russo, M. J. (2018). Direct and indirect effects of child abuse and environmental stress: A lifecourse perspective on adversity and depressive symptoms. American Journal of Orthopsychiatry, 88(2), 180-188.

StataCorp. (2019). Stata data management reference manual: Release 16 (p. 112). College Station, TX: StataCorp LLC.

Sullivan, M. (2020). Don't nag your husband during lockdown, Malaysia's government advises women. https:/www.npr.org/2020/04/01/825051317/dont-nag-your-husband-during-lock-down-malaysiasgovernment-advises-women (accessed April 6, 2020).

Texas Family Code $\S 17.001$ (2019). https://statutes.capitol.texas.gov/Docs/FA/pdf/FA.71.pdf (accessed March 5, 2020).

Townsend, M. (April 4, 2020). The Guardian. Domestic abuse cases soar as lockdown takes its toll. https:/www.theguardian.com/world/2020/apr/04/domestic-abuse-cases-soar-as-lockdown-takes-its-toll (accessed April 5, 2020).

U.S. Department of Health \& Human Services (2020). Administration for children and families, administration on children, youth and families, children's bureau. child maltreatment 2018. Available from https://www.acf.hhs.gov/cb/research-data-technology/statistics-research/child-maltreatment.

United Nations. 2020. UN chief calls for domestic violence 'ceasefire' amid 'horrifying global surge'. https://news.un.org/en/story/2020/04/1061052 (accessed April 6, 2020).

United Nations Women. (2020). Covid-19 and ending violence against women and girls. New York: United Nations https://www.unwomen.org/-/media/headquarters/attachments/sections/library/publications/2020 /issue-brief-covid-19-and-ending-violence-against-women-and-girls-en.pdf?la=en\&vs=5006 (accessed April 7, 2020).

Vanderminden, J., Hamby, S., David-Ferdon, C., Kacha-Ochana, A., Merrick, M., Simon, T. R., et al. (2019). Rates of neglect in a national sample: Child and family characteristics and psychological impact. Child Abuse \& Neglect, 88, 256-265.

Wagers, S. (April 8, 2020). Domestic violence growing in wake of coronavirus outbreak. https://theconversation.com/domestic-violence-growing-in-wake-of-coronavirus-outbreak-135598 (accessed April 8, 2020).

Weichselbaum, S., \& Li, W. (2020, March 27). As coronavirus surges, crime declines in some cities [The Marshall Project]. https://www.themarshallproject.org/2020/03/27/as-coronavirus-surges-crime-declinesin-some-cities (accessed April 30, 2020).

Widom, C. S., Fisher, J. H., Nagin, D. S., \& Piquero, A. R. (2018). A prospective examination of criminal career trajectories in abused and neglected males and females followed up into middle adulthood. Journal of Quantitative Criminology, 34, 831-852. https://doi.org/10.1007/s10940-017-9356-7. 
Publisher's Note Springer Nature remains neutral with regard to jurisdictional claims in published maps and institutional affiliations.

Alex R. Piquero is Professor and Chair of the Department of Sociology and Arts \& Sciences Distinguished Scholar at The University of Miami and Professor of Criminology at Monash University in Melbourne Australia. He is also editor of Justice Evaluation Journal. His research interests include criminal careers, criminological theory, crime policy, evidence-based crime prevention, and quantitative research methods. He has received several research, teaching, and service awards and is fellow of both the American Society of Criminology and the Academy of Criminal Justice Sciences. He has received several research, teaching, and mentoring awards and in 2019, he received the Academy of Criminal Justice Sciences Bruce Smith, Sr. Award for outstanding contributions to criminal justice.

Jordan R. Riddell is a PhD student in the Criminology and Criminal Justice Program in the School of Economic, Political and Policy Sciences at The University of Texas at Dallas. His research interests include the spatial-temporal analysis of crime and criminal justice education.

Stephen A. Bishopp received his PhD (2013) in Criminology from the University of Texas at Dallas. He is also a Sergeant and 30-year veteran of the Dallas Police Department. He holds an appointment as Adjunct Assistant Professor at the University of Texas School of Public Health. His research interests include police mental health/well-being, police behavior and use of force, and criminological theory.

Chelsey Narvey is an incoming Assistant Professor at Sam Houston State University. Her research interests include criminological theory, corrections, and developmental/life-course criminology, and she does work at the intersection of corrections and life-course theory. She has published on telemedicine and the way it can be used in correctional settings. Some of her work can be found in the Journal of Correctional Healthcare, as well as in Aggression \& Violent Behavior. In 2019, she won the Distinguished Instruction by a Teaching Assistant Award in her school.

Joan A. Reid is an Associate Professor at the University of South Florida St. Petersburg, Director of the USF Human Trafficking Risk to Resilience Research Lab and a Licensed Mental Health Counselor in the State of Florida. Her research concerns include family violence, child sex trafficking, trauma-informed care and recovery of crime victims. Her research has appeared in Child Maltreatment, American Journal of Public Health, Justice Quarterly and Criminal Behaviour and Mental Health.

Nicole Leeper Piquero is Professor of Sociology and Associate Dean for Program Development in the College of Arts \& Sciences at the University of Miami. She received her Ph.D. in Criminology and Criminal Justice from the University of Maryland. Her research focuses on the study of white-collar and corporate crimes, criminological theory, as well as gender and crime. 